\title{
In vitro cytotoxicity of chemical preservatives on human fibroblast cells
}

\author{
Daniel Gonsales Spindola ${ }^{1,3}$, Andre Hinsberger ${ }^{1}$, Valéria Maria de Souza Antunes ${ }^{1,2}$, \\ Luis Felipe Gomes Michelin ${ }^{4}$, Claudia Bincoletto ${ }^{3}$, Carlos Rocha Oliveira ${ }^{1,2,3^{*}}$
}

\begin{abstract}
${ }^{1}$ Grupo de Fitocomplexos e Sinalização Celular, Escola de Ciências da Saúde, Universidade Anhembi Morumbi, São Paulo/SP, Brasil, ${ }^{2}$ Instituto de Osmologia e Óleos Essenciais, Minas Gerais, Brasil, ${ }^{3}$ Departamento de Farmacologia, Escola Paulista de Medicina (EPM), Universidade Federal de São Paulo (UNIFESP), São Paulo/SP, Brasil, ${ }^{4}$ Centro Interdisciplinar de Investigação Bioquímica, Universidade de Mogi das Cruzes, Mogi das Cruzes, São Paulo/SP, Brasil
\end{abstract}

\begin{abstract}
Preservatives are widely used substances that are commonly added to various cosmetic and pharmaceutical products to prevent or inhibit microbial growth. In this study, we compared the in vitro cytotoxicity of different types of currently used preservatives, including methylparaben, imidazolidinyl urea (IMU), and sodium benzoate, using the human newborn fibroblast cell line CCD1072Sk. Of the tested preservatives, only IMU induced a reduction in cell viability, as shown using the MTT assay and propidium iodide staining (IMU>methylparaben>sodium benzoate). IMU was shown to promote homeostatic alterations potentially related to the initiation of programed cell death, such as decreased mitochondrial membrane potential and caspase- 3 activation, in the treated cells. Methylparaben and sodium benzoate were shown to have a very low cytotoxic activity. Taken together, our results suggest that IMU induces programed cell death in human fibroblasts by a canonical intrinsic pathway via mitochondrial perturbation and subsequent release of proapoptotic factors.
\end{abstract}

Keywords: Preservatives. Pharmaceutical/chemistry. Fibroblasts/cytotoxicity. Cell death/drug effects. Cosmetics/additives.

\section{INTRODUCTION}

Preservatives are chemical substances that inhibit the overgrowth of microorganisms to maintain the stability of a product (Brasil, 2001) and increase its shelf life (Rebello, 2005). Cosmetic industry primarily benefits from this because cosmetic products must be safe for the users owing to their topical application and extensive contact with the skin (Orton, Wilkinson, 2004). Inhibition of microbial contamination ensures that a pharmaceutical formulation maintains its physical and chemical properties as well (Gonçalves, 2010). In Brazil, sanitary regulations, RDC n.29/2012 lists, permit preservatives such as parabens, sodium benzoate (SB), and imidazolidinyl urea (IMU).

Methylparaben (MP) is a preservative often used in cosmetic, pharmaceutical, and food products because of

\footnotetext{
*Correspondence: C. R. Oliveira. Escola de Ciências da Saúde, Universidade Anhembi Morumbi. Rua Dr. Almeida Lima, 1.134, CEP: 03164-000. São Paulo, SP, Brasil. E-mail: carlos.oliveira@anhembimorumbi.edu.br
}

its microbicidal, bacteriostatic, and fungistatic activities (Ozaki et al., 2012; Rowe, Sheskey, Quinn, 2009). During the last decade, parabens have fallen into discredit, perhaps due to some cases of dermatitis or endocrine disruptive mechanisms, showing their estrogenic actions, including increased breast cancer cell proliferation that could be inhibited by the application of an antiestrogenic compound (Castelain, Castelain, 2012; Mowad, 2000; Bordel-Gómez, Miranda-Romero, Castrodeza-Sanz, 2010; Okubo, 2001; Byford et al., 2002). This prompted cosmetic laboratories to modify the spectrum of preservatives in use (Thyssen et al., 2010).

However, according to Soni, Carabin, and Burdock (2005), the possible estrogenic hazard of parabens, based on the results of previous studies, is equivocal, and the metabolism and elimination rates of parabens, which are dose, route, and species dependent, are not considered. Developmental toxicity studies in several species, using MP, showed no teratological effects. Despite the controversial endocrine system-disrupting activity of MP and ethylparaben, food, pharmaceutical, 
and cosmetic industries are under pressure due to the negative public opinion and are responding by replacing parabens with other biocides that cause multiple cases of allergic contact sensitization, which at times even reach worldwide epidemic proportions (Sasseville, Alfalah, Lacroix, 2015).

Formaldehyde releasers are widely used as preservatives, particularly in cosmetic products, replacing free formaldehyde that can strongly sensitize the skin (Latorre et al., 2011). The main molecules of this group are quaternium-15, IMU, diazolidinyl urea, DMDM hydantoin (dimethylhydantoin), and Bronopol (Statham et al., 2010). These substances can slowly release formaldehyde such that its concentration in the product is very low but sufficiently high to inhibit the overgrowth of microbes (Kireche, Gimenez-Arnau, Lepoittevin, 2010). A study conducted by Groot and Veenstra (2010) indicated that IMU is the most used formaldehyde releaser in the USA and Europe. However, this substance is known to induce allergic contact dermatitis (Bordel-Gómez, MirandaRomero, Castrodeza-Sanz, 2010; Groot, Veenstra, 2010; García-Gavín et al. 2010).

$\mathrm{SB}$, a sodium salt of benzoic acid, is used as an antimicrobial preservative that exhibits antifungal activity attributed to the non-dissociated benzoic acid (Rowe, Sheskey, Quinn 2009). As a part of pharmaceutical formulations, preservatives are topically applied to the human skin; thus, the study of the possible mechanisms of actions and health risks that the preservatives may pose to the population is important to substantiate the knowledge about these compounds. The present study aimed to evaluate the cytotoxicity of different types of preservatives using a newborn fibroblast cell line, CCD1072Sk (Figure 1).

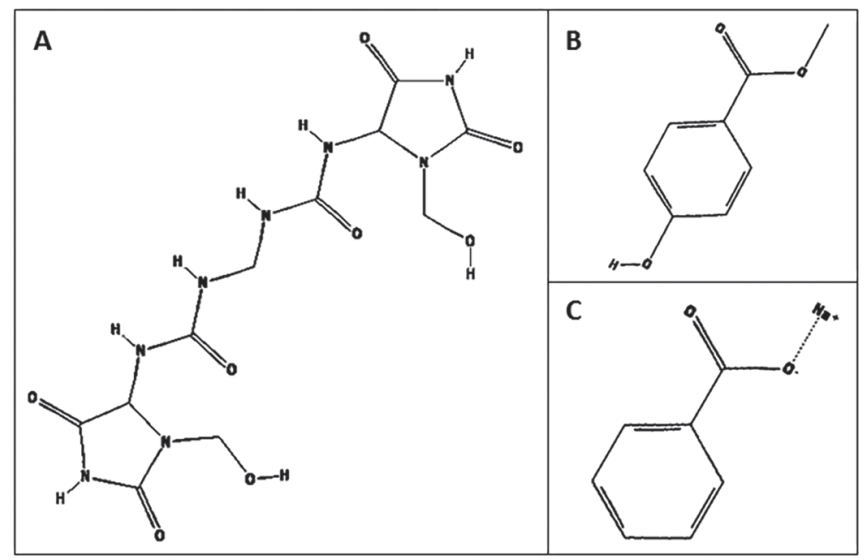

FIGURE 1 - Chemical structures of studied compounds. (A) Imidazolidinyl urea, (B) methylparaben, and (C) sodium benzoate. Source, PubChem (2005a,b,c).

\section{MATERIAL AND METHODS}

\section{Chemicals and preservatives}

The preservatives MP, IMU, and SB were generously provided by Labsynth Ltda. (Diadema, Brazil). Working concentrations were determined according to the recommendations of the European Commission of Health and Food Safety. In addition to the concentrations within the safety guidelines, concentrations 10 -fold higher and lower than the safety threshold were used. Therefore, cells were treated with each preservative at the concentrations of $0.01 \%, 0.1 \%$, and 1\% (weight/volume) (European Comission, 2011; Heydaryinia, Veissi, Sadadi, 2011).

The Annexin V/fluorescein isothiocyanate (FITC) Apoptosis Detection Kit was acquired from BD Pharmigen (CA, USA). Iscove's modified Dulbecco's medium (IMDM) and all cell culture reagents were bought from Gibco (USA). Anti-cleaved caspase-3 (Asp175) primary and Alexa Fluor 488-conjugated secondary antibodies were from Cell Signaling Technology (MA, USA). Carbonyl cyanide $p$-(trifluoromethoxy)phenylhydrazone (FCCP) was purchased from Sigma Chemical Co. (St. Louis, MO, USA). Tetramethylrhodamine ethyl ester (TMRE), Fura-2AM, and 2,7-dichlorodihydrofluorescein diacetate (DCFH-DA) were purchased from Molecular Probes (Eugene, OR, USA).

\section{CCD1072Sk cell cultures}

The CCD1072Sk cell line was obtained from Rio de Janeiro Cell Bank (CCD1072Sk - ATCC CRL2088). This cell line was selected because of the ease of acquisition, handling, and its stability even after many passages. Furthermore, fibroblasts (human or murine) are widely used for the evaluation of the cytotoxicity induced by the components of cosmetic formulations, which allows the comparison between our results and the existing data (Jin et al., 2008; Urcan et al., 2010; Tomankova et al., 2011).

The cells were cultured in a monolayer using IMDM (Gibco) supplemented with 10\% fetal bovine serum(FBS), $100 \mathrm{UI} / \mathrm{mL}$ penicillin/streptomycin, and $0.25 \mu \mathrm{g} / \mathrm{mL}$ Fungizone (Gibco) in a humidified atmosphere at $37{ }^{\circ} \mathrm{C}$ in $5 \% \mathrm{CO}_{2}$. These cells were trypsinized three times per week using $0.25 \%$ trypsin/EDTA (Cultilab, Brazil). For the 24-hour cell viability assessment, the control and treated cells were centrifuged and resuspended in equal parts medium and trypan blue $(0.05 \%$ solution $)$ and counted using a hemocytometer. 


\section{Evaluation of cytotoxicity using MTT}

Cell viability was measured using the standard methylthiazol tetrazolium (MTT) assay, as previously described by Mosmmann (1983). In brief, $5 \times 10^{4}$ viable cells were seeded in clear 96-well flat-bottom plates (Corning, USA) using IMDM supplemented with $10 \%$ FBS and incubated with different concentrations of the preservatives for 24 hours. Afterward, $10 \mu \mathrm{L}$ of MTT was added to each well $(5 \mathrm{mg} / \mathrm{mL} /$ well $)$ and incubated for 4 hours. Following the incubation, $150 \mu \mathrm{L}$ of $10 \%$ sodium dodecyl sulfate solution in MiliQ $\mathrm{H}_{2} \mathrm{O}$ was added to each well and incubated overnight at $37^{\circ} \mathrm{C}$ to solubilize the formazan crystals. The absorbance was measured at 595 nm using a FlexStation 3 Multi-Mode Benchtop Reader (Molecular Devices, Sunnyvale, CA, USA).

\section{Evaluation of cell cycle effects using propidium iodide staining}

For cell cycle analysis, $5 \times 10^{5} \mathrm{CCD} 1072 \mathrm{Sk}$ cells were seeded in 6-well plates and incubated with different concentrations of the preservatives for 24 hours. These cells were then harvested, washed with phosphate-buffered saline (PBS), and fixed in 50\% ice-cold ethanol for 30 minutes. The fixed cells were resuspended in RNase/PBS solution $(20 \mu \mathrm{g} / \mathrm{mL})$ for 30 minutes, after which propidium iodide (PI) was added to each sample at a concentration of $50 \mu \mathrm{g} / \mathrm{mL}$. Following this, $10^{5}$ events were analyzed using a BD FACSCalibur Flow Cytometry System (BectonDickinson, Mountain View, CA, USA). Data was acquired using the CellQuest software (Becton-Dickinson), and the results were analyzed using the FlowJo software (Tree Star, Oregon, USA).

\section{Cell death analysis by flow cytometry using Annexin V-FITC/PI staining}

CCD1072Sk cells treated with different concentrations of the preservatives for 24 hours were stained with FITC-conjugated Annexin V and PI according to the manufacturer's instructions (Annexin V/FITC Apoptosis Detection Kit, BD Pharmingen, $\mathrm{CA}$, USA). The populations of Annexin $\mathrm{V}^{-} / \mathrm{PI}^{-}$(viable cells), Annexin $\mathrm{V}^{+} / \mathrm{PI}^{-}$(indicative of apoptosis), Annexin $\mathrm{V}^{-} / \mathrm{PI}^{+}$(indicative of necrosis), and Annexin $\mathrm{V}^{+} / \mathrm{PI}^{+}$ (indicative of necroptosis) cells were evaluated by flow cytometry using a BD FACSCalibur flow cytometer. Data was acquired using the CellQuest software, and the results were analyzed using the FlowJo software (Tree Star).

\section{Determination of the mitochondrial membrane potential $(\Delta \Psi \mathrm{m})$ using flow cytometric analysis.}

The mitochondrial membrane potential $(\Delta \Psi \mathrm{m})$ was measured in the treated CCD1072Sk cells using flow cytometric analysis. These cells were collected in FACS tubes (BD Biosciences Discovery Labware, MA, USA) and stained with TMRE $(50 \mathrm{nM})$ for $20 \mathrm{~min}$. Following this, $10^{5}$ events were analyzed using a BD FACSCalibur flow cytometer. Data was acquired using the CellQuest software. Log scale fluorescence histograms were analyzed for the median relative fluorescent unit (RFU) intensity using the FlowJo software.

\section{Cleaved caspase- 3 levels in the treated cells}

Caspase-3 activation was evaluated in CCD1072Sk cells treated with the investigated preservatives for 24 hours using the flow cytometric analysis of endogenous levels of the caspase-3 large fragment (17/19 kDa) according to the manufacturer's instructions (Cell Signaling Technology). These cells were stained with anti-cleaved caspase-3 (Asp175) primary and Alexa Fluor 488-conjugated secondary antibodies for 1 hour in the dark. Following this, $10^{5}$ events were analyzed using a BD FACSCalibur flow cytometer. Data was acquired using the CellQuest software, and the results were analyzed using FlowJo software.

\section{Statistical analysis}

The obtained results were expressed as the mean \pm standard error of mean (SEM) from at least three independent experiments, unless stated otherwise. Paired data was evaluated by Student's $t$-test. One-way analysis of variance (ANOVA) was used for multiple comparisons. A $p$ value of $<0.05$ was considered significant.

\section{RESULTS AND DISCUSSION}

Preservatives are biocidal chemicals added to cosmetic products, topical medications, and other pharmaceuticals to protect them against microbial spoilage and to protect the users against infection (Sasseville, 2004). The results of the present study show that only IMU exhibited cytotoxic activity against the investigated fibroblasts. According to the results presented in Figure 2A, IMU significantly reduced cell viability at a concentration of $1 \%$, as shown using the MTT assay, which shows the activity of succinate dehydrogenase and the reduction rate of the tetrazolium salt into insoluble formazan crystals 
(Mosmann, 1983). Subsequent testing was performed using the same concentration of all preservatives to confirm their activities on different cellular pathways.

PI staining is used to label DNA in the investigated cells, allowing the observation of cell cycle phases as well as the fraction of hypodiploid cells belonging to the sub-G1 phase. This fraction comprises dead or dying cells in which the DNA content is diminished possibly due to DNA fragmentation, a classical feature of apoptosis
(Riccardi, Nicoletti, 2006). According to Shu et al. (2002), exposure to ionizing radiation, chemical product treatment, and oxidative stress represent the possible causes leading to cellular stagnation in the sub-G1 phase. IMU (1\%) treatment led to a significant increase in the percentage of cells in the sub-G1 phase, indicating cell death (Figure 2B and $2 \mathrm{C}$ ). The observed higher levels of cell death determined here in contrast to those determined using the MTT assay are due to the PI staining of the genetic

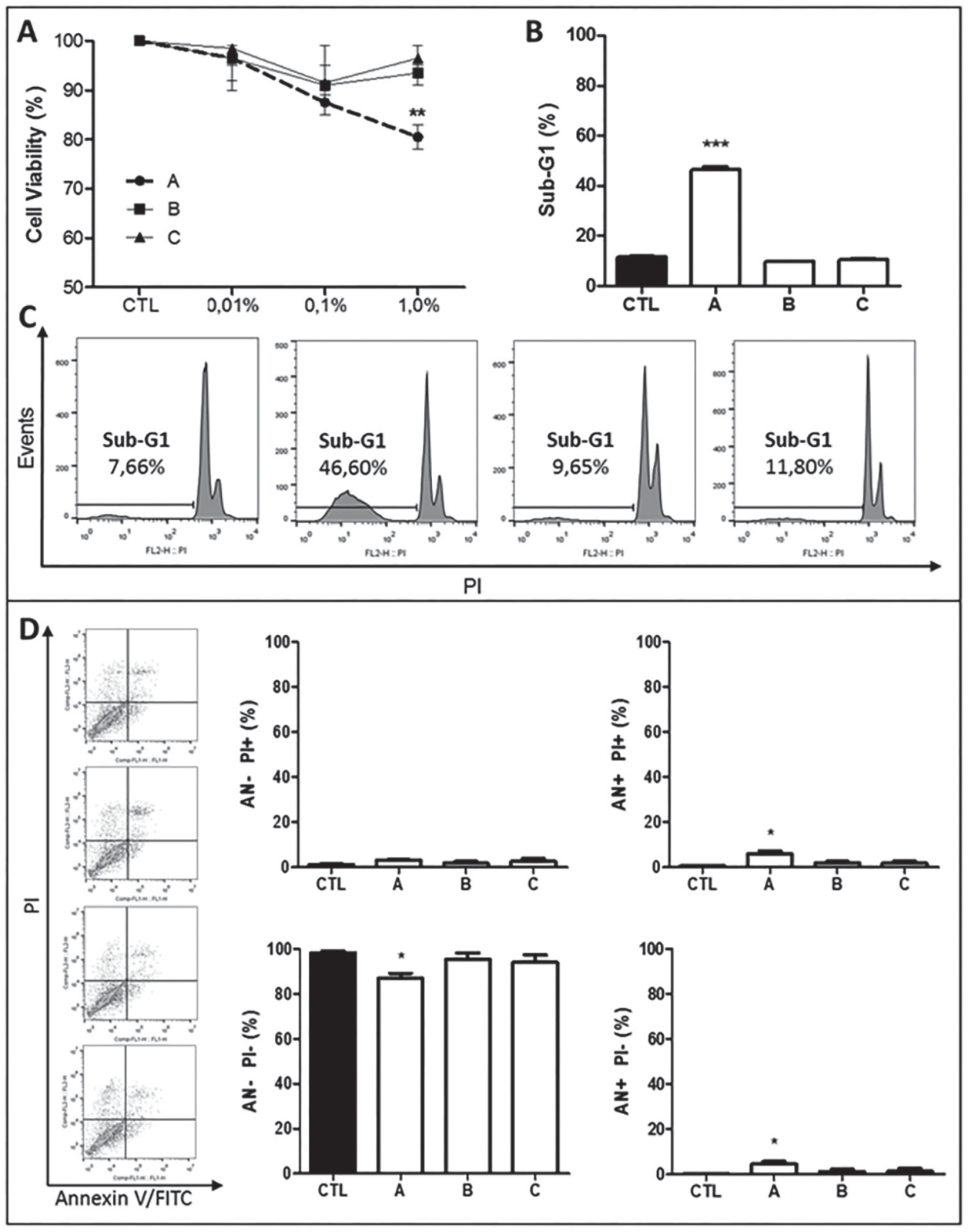

FIGURE 2 - (A) CCD1072Sk cell viability and cell death analyses following the exposure to preservatives. Cells were treated with imidazolidinyl urea (A), methylparaben (B), and sodium benzoate $(\mathbf{C})$ at the concentrations of $0.01 \%, 0.1 \%$, and $1.0 \%$ for 24 h. (B and C) Percentage of the treated cells in the sub-G1 phase and related histograms. (D) Representative histograms of the treated CCD1072Sk cells labeled simultaneously with Annexin V-FITC and PI and the results of quantification. *p $<0.05$, **p $<0.01$, and $* * * p<0.001$ compared with the untreated control (one-way analysis of variance/Tukey test). Results were analyzed using FlowJo v.10.0 and GraphPad Prism 5 software. 
material of the treated cells rather than the assessment of the mitochondrial enzyme functions (Riccardi, Nicoletti, 2006; Mosmann, 1983; Vermes et al., 1995).

To determine the cell death type induced by preservatives, we used the Annexin V-FITC/PI double staining test. A significant increase in Annexin $\mathrm{V}^{+} / \mathrm{PI}^{+}$ and Annexin $\mathrm{V}^{+} / \mathrm{PI}^{-}$cellular fractions, of about $15 \%$ and $10 \%$, respectively, was observed in samples treated with IMU compared with that observed in the untreated group (Figure 2D). These results indicate that IMU induces programmed cell death in CCD1072Sk cells. In contrast, cells treated with MP and SB did not undergo the externalization of phosphatidylserine, a marker of apoptosis. Finally, the investigated preservatives did not induce a significant increase in the Annexin $\mathrm{V}^{-} / \mathrm{PI}^{+}$ population, which is a fraction of cells with permeabilized membranes, suggesting the induction of necrotic cell death (Nikoletopoulou et al., 2013).

Considering the cytotoxicity of IMU and the induction of different cell death pathways, previous studies have described that this compound induces apoptosis. Anselmi et al. (2002) reported the induction of apoptosis and necrosis in human promyelocytic leukemia HL60 cells by four preservatives, including IMU. IMU at low concentrations $(0.01 \%$ and $0.1 \%)$ led to a significant reduction in the viability of HL60 cells, together with an increase in the apoptosis marker levels. However, at higher concentrations $(0.5 \%-1 \%)$, necrosis was detected as the predominant cell death type.

Mitochondria are involved in the processes of cell survival, development, and death due to many intracellular signaling pathways contributing to ATP synthesis, calcium homeostasis, reactive oxygen species (ROS) production, and others (Tait, Green, 2010). Dewson and Kluck (2009) described that the receptor binding of extracellular death ligands induces the oligomerization of proapoptotic $\mathrm{BH} 3$-only proteins (Bax, Bak) in the cytosol with the subsequent formation of a pore in the mitochondrial outer membrane. Mitochondrial outer membrane permeabilization results in the release of apoptosis-inducing intermembrane proteins (e.g., cytochrome $c$, SMAC/DIABLO, and AIF) into the cytosol and ultimately leads to apoptosis. $(\Delta \psi \mathrm{m})$ is directly linked to the integrity of the mitochondrial membrane and transition pore opening, leading to the loss of potential and water influx into the mitochondrial matrix, which further results in the loss of mitochondrial function (Gottlieb, Vander Heiden, Thompson, 2000). In many cell types, this process is crucial for apoptosis initiation (Ferri, Kroemer, 2001; Fulda, Debatin, 2006). Therefore, $\Delta \psi \mathrm{m}$ determination allows the indirect evaluation of mitochondrial integrity, thereby contributing to the initiation and perpetuation of cell death.

To detect the role of mitochondria in preservativeinduced cell death, CCD1072Sk cells were treated with $1 \%$ preservative concentrations for $6 \mathrm{~h}$, and $\Delta \psi \mathrm{m}$ was assayed by determining the TMRE incorporation. TMRE is a lipophilic cationic dye that readily accumulates inside the active mitochondria; however, it is not sequestered by depolarized mitochondria (Scaduto Jr., Grotyohann, 1999; Alirol, Martinou, 2006). FCCP, a strong ionophore uncoupler of oxidative phosphorylation, was used as a positive control of mitochondrial depolarization. FCCP interrupts ATP synthesis by transporting protons across the internal mitochondrial membrane, resulting in the complete dissipation of mitochondrial membrane potential (Zablockaite et al., 2007). Our results demonstrated that the 6-h IMU treatment leads to a significant reduction of $\Delta \psi \mathrm{m}$, indicating the involvement of the mitochondrial cell death pathway (Figure 3A and 3B).

Activation of caspases is a hallmark of apoptosis. Caspase- 3 is one of the main caspases believed to be a key enzyme in programed cell death processes (Cohen, 1997; Olsson, Zhivotovsky, 2011; Mcilwain, Berger, Mak, 2013). Here, previous results indicated that caspase-3 is most likely activated in response to the release of mitochondrial intermembrane space proteins. To confirm this, CCD1072Sk cells were treated with the preservatives at the concentrations of $1 \%$ for $24 \mathrm{~h}$, and anti-cleaved caspase- 3 antibodies were used for the detection of this protein. IMU significantly activated caspase- 3 in comparison with other preservatives (Figure 3C and 3D), indicating that fibroblasts undergo caspase-dependent cell death following this treatment, most likely induced by the activation of mitochondrial pathway.

In agreement with our results, Yadav et al. (2016) showed previously that $\mathrm{SB}$ is not cytotoxic on splenocytes at concentrations of up to $1 \mathrm{mg} / \mathrm{mL}$. However, Park et al. (2011), using rat cortical neuron cell primary cultures, reported that the viability of these cells decreases following the preservative treatment. Furthermore, as a hydroxyl scavenger, SB was shown to decrease drug cytotoxicity in a manner similar to hydroxyurea in L5178Y leukemia cells (Przybyszewski, Kopeć-Szlezak, Malec, 1987), partly explaining the lack of apoptotic marker activation by SB in our study.

Finally, we showed that MP did not demonstrate cytotoxicity against the studied cells. These results are supported by the results described by Smith and Alexander (2005) who studied relative cytotoxicity of preservative systems, including the isothiazolinone 


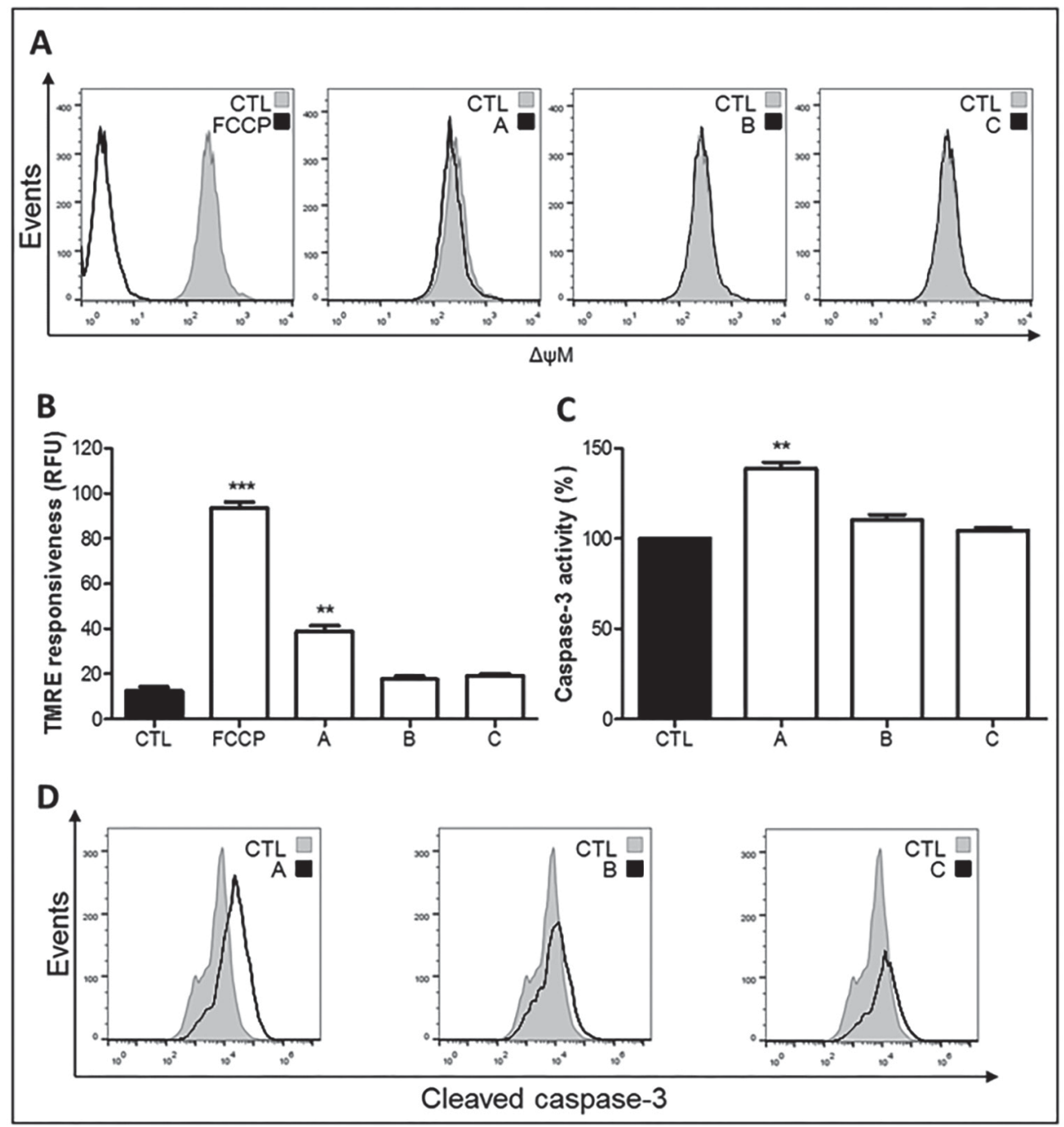

FIGURE 3 - (A) Representative histograms and (B) the respective bar plots showing the loss of $\triangle \Psi \mathrm{m}$ in CCD1072Sk cells treated for $6 \mathrm{~h}$ with $1 \%$ preservatives: imidazolidinyl urea (A), methylparaben (B), and sodium benzoate (C). FCCP was used as positive control. $* * p<0.01$ and $* * * p<0.001$ compared with the untreated control group (one-way analysis of variance/Tukey test). (C) Percentage of caspase-3 activation and (D) representative histograms of CCD1072Sk cells treated with the same preservatives. $* * \mathrm{p}<0.01$ compared with the untreated control (one-way analysis of variance/Tukey test).

family (a formaldehyde donor), parabens, and mixtures of organic acids against BALB/C mouse fibroblast cells after 1 hour of exposure. Parabens were shown to have lower cytotoxicity on these cells than the other preservatives tested. Other studies confirmed the low toxicity of parabens as well, including that of Soni, Carabin, and Burdock (2005) who showed that methyl and propylparaben at the concentrations of $0.25 \%$ and $0.05 \%$, respectively, did not induce hemolysis in human and rabbit erythrocytes. In contrast, Carvalho et al. (2012) evaluated the potential of some preservatives for the induction of apoptosis, necrosis, and genotoxicity against HDF cells (human fibroblasts) following the 24hours of exposure. Their results showed that methyl and propylparaben have increased genotoxic potential. These results differ from the results reported in this study most likely because of the use of different cell lines, reagents, methodologies, exposure times, and concentrations of preservatives.

\section{CONCLUSION}

Cytotoxicity and safety assessment of preservatives frequently used in pharmaceutical products are important parameters that need to be evaluated because they can help elucidate the mechanisms of action of products that are regularly consumed by a wide population of users. In this study, we showed that IMU has cytotoxic effects on human fibroblasts. Moreover, IMU treatment of human 
fibroblasts was shown to result in an increased cell death level, a significant increase in DNA fragmentation, externalization of phosphatidylserine, and activation of caspase-3. Furthermore, the significant depolarization of mitochondria induced by IMU suggests that the main stimulus for the initiation of programmed cell death is the release of mitochondrial proteins into the cytosol following outer membrane permeabilization. MP and SB did not show cytotoxicity on human fibroblasts under the conditions used here. Our data indicate that human fibroblasts are more resistant to the exposure to MP and $\mathrm{SB}$ in comparison with that to IMU under the same test conditions.

\section{ACKNOWLEDGMENTS}

This work was supported by grants from the Conselho Nacional de Desenvolvimento Científico e Tecnológico (CNPq) and CAPES. The authors thank Synth Laboratory for its material support for this research.

\section{REFERENCES}

Alirol E, Martinou JC. Mitochondria and cancer: is there a morphological connection? Oncogene. 2006;25(34):4706-16.

Anselmi C, Ettorre A, Andreassi M, Centini M, Neri P, Di Stefano A. In vitro induction of apoptosis vs. necrosis by widely used preservatives: 2-phenoxyethanol, a mixture of isothiazolinones, imidazolidinyl urea and 1,2-pentanediol. Biochem Pharmacol. 2002;63(3):437-53.

Bordel-Gómez MA, Miranda-Romero A, Castrodeza-Sanz J. Epidemiology of contact dermatitis: prevalence of sensitization to different allergen and associated factors. Actas DermoSifiliogr. 2010;101(1):59-75.

Brasil. Agência Nacional de Vigilância Sanitária. Resolução n.162, de 12 de setembro de 2001. Lista de conservantes permitidos para produtos de higiene pessoal, cosméticos e perfumes. Diário Oficial da União, 12 set 2001; Seção 1.

Byford JR, Shaw LE, Drew MG, Pope GS, Sauer MJ, Darbre PD. Oestrogenic activity of parabens in MCF7 human breast cancer cells. J Steroid Biochem Mol Biol. 2002;80(1):49-60.

Carvalho CM, Menezes PM, Letenski GC, Praes CE, Feferman $\mathrm{IH}$, Lorencini M. In vitro induction of apoptosis, necrosis and genotoxicity by cosmetic preservatives: application of flow cytometry as a complementary analysis by NRU. Int J Cosmet Sci. 2012;34(2):176-82.
Castelain F, Castelain M. Parabens: a real hazard or a scary story? Eur J Dermatol. 2012;22(6):723-7.

Cohen GM. Caspases: the executioners of apoptosis. Biochem J. 1997;326(pt 1):1-16.

Dewson G, Kluck RM. Mechanisms by which Bak and Bax permeabilize mitochondria during apoptosis. J Cell Sci. 2009;122(pt16):2801-8.

European Comission. Scientific Comittee on Consumer Safety. Opinion on parabens. 2011. (COLIPA n.P82) (SCCS/1348/10 Revision 22 March 2011). Available from: http://ec.europa. $\mathrm{eu} /$ health/scientific_committees/consumer_safety/docs/ sccs_o_041.pdf.

Ferri KR, Kroemer G. Organelle-specific initiation of cell death pathways. Nat Cell Biol. 2001;3(11):255-63.

Fulda S, Debatin KM. Extrinsic versus intrinsic apoptosis pathways in anticancer chemotherapy. Oncogene. 2006;25(34):4798-811.

García-Gavín J, González-Vilas D, Fernández-Redondo V, Toribo J. Allergic contact dermatitis in a girl due to several cosmetics containing diazolidinyl-urea or imidazolidinyl-urea. Contact Dermatitis. 2010;63(1):49-50.

Gonçalves SD. Razões para preservar cosméticos. São Paulo: Proserv Química;2010. p.22.

Gottlieb E, Vander Heiden MG, Thompson CB. Bcl-XL prevents the initial decrease in mitochondrial membrane potential and subsequent reactive oxygen species production during tumor necrosis factor alpha-induced apoptosis. Mol Cell Biol. 2000;20(15):5680-9.

Groot AC, Veenstra M. Formaldehyde-releasers in cosmetics in the USA and in Europe. Contact Dermatitis. 2010;62(4):221-4.

Heydaryinia A, Veissi M, Sadadi A. A comparative study of the effects of the two preservatives, sodium benzoate and potassium sorbate on Aspergillus niger and Penicillium notatum. Jundishapur J Microbiol. 2011;4(4):301-7.

Jin CY, Zhu BS, Wang XF, Lu QH. Cytotoxicity of titanium dioxide nanoparticles in mouse fibroblast cells. Chem Res Toxicol. 2008;21(9):1871-7. 
Kireche M, Gimenez-Arnau E, Lepoittevin J. Preservatives in cosmetics: reactivity of allergenic formaldehyde-releasers to-ward amino acids through breakdown products other than formaldehyde. Contact Dermatitis. 2010;63(4):192-202.

Latorre N, Borrego L, Fernández-Redondo V, García-Bravo B, Giménez-Arnau AM, Sánchez J, Silvestre JF. Patch testing with formaldehyde and formaldehyde-releasers: multicentre study in Spain (2005-2009). Contact Dermatitis. 2011;65(5):286-92.

Mcilwain DR, Berger T, Mak TW. Caspase functions in cell death and disease. Cold Spring Harb Perspect Biol. 2013;5(4, a008656):1-29.

Mosmann T. Rapid colorimetric assay for cellular growth and survival: application to proliferation and cytotoxicity assays. $\mathrm{J}$ Immunol Methods. 1983;65(1/2):55-63.

Mowad CM. Allergic contact dermatitis caused by parabens: 2 case reports and a review. Am J Contact Dermat. 2000;11(1):53-6.

Nikoletopoulou V, Markaki M, Palikaras K, Tavernarakis N. Crosstalk between apoptosis, necrosis and autophagy. Biochim Biophys Acta. 2013;1833(12):3448-59.

Okubo T, Yokoyama Y, Kano K, Kano I. ER-dependent estrogenic activity of parabens assessed by proliferation of human breast cancer MCF-7 cells and expression of ER $\alpha$ and PR. Food Chem Toxicol. 2001;39(12):1225-32.

Olsson M, Zhivotovsky B. Caspases and cancer. Cell Death Differ. 2011;18(9):1441-9.

Orton DI, Wilkinson JD. Cosmetic allergy: incidence, diagnosis and management. Am J Clin Dermatol. 2004;5(5):327-37.

Ozaki H, Sugihara K, Watanabe Y, Fujino C, Uramaru N, Sone T, Ohta S, Kitamura S. Comparative study of the hydrolytic metabolism of methyl-, ethyl-, propyl-, butyl-, heptyl- and dodecylparaben by microsomes of various rat and human tissues. Xenobiotica. 2012;43(12):1064-72.

Park HW, Park EH, Yun HM, Rhim H. Sodium benzoatemediated cytotoxicity in mammalian cells. J Food Biochem, 2011; 35(4):1034-46.

Przybyszewski WM, Kopeć-Szlezak J, Malec J. Protection of L5178Y cells by vitamin E against acute hydroxyurea toxicity does not change the efficiency of ribonucleotide reductasemediated hydroxyurea-induced cytotoxic events. Cancer Lett. 1987; 34(3):337-44.
PubChem. Imidazolidinyl Urea. [cited 2005a Jul 19]. Available from: https://pubchem.ncbi.nlm.nih.gov/compound/38258. (accessed Jun 14, 2016).

PubChem. Methyl 4-hydroxybenzoate. [cited 2005b Mar 26]. Available from: https://pubchem.ncbi.nlm.nih.gov/ compound/7456. (accessed Jun 14, 2016).

PubChem. Sodium Benzoate. [cited 2005c Mar 27]. Available from: https://pubchem.ncbi.nlm.nih.gov/compound/517055. (accessed Jun 14, 2016).

Rebello T. Guia de produtos cosméticos. $6^{\text {th }}$ ed. São Paulo: Senac; 2005. 161 p.

Riccardi C, Nicoletti I. Analysis of apoptosis by propidium iodide staining and flow cytometry. Nat Protoc. 2006;1(3):1458-61.

Rowe RC, Sheskey PJ, Quinn ME. Handbook of pharmaceutical excipients. $6^{\text {th }}$ ed. London: Pharmaceutical Press; 2009. 888 p.

Sasseville D, Alfalah M, Lacroix JP. "Parabenoia” debunked, or "Who's afraid of Parabens?” Dermatitis. 2015;26(6):254-9.

Sasseville D. Hypersensitivity to preservatives. Dermatol Ther. 2004;17(3):251-61.

Scaduto Jr. RC, Grotyohann LW. Measurement of mitochondrial membrane potential using fluorescent rhodamine derivatives. Biophys J. 1999;76(pt 1):469-77.

Shu B, Wu Z, Hao L, Zeng D, Feng G, Lin Y. Experimental study on He-Ne laser irradiation to inhibit scar fibroblast growth in culture. Chin J Traumatol. 2002;5(4):246-9.

Smith CN, Alexander BR. The relative cytotoxicity of personal care preservative systems in Balb/C 3T3 clone A31 embryonic mouse cells and the effect of selected preservative systems upon the toxicity of a standard rinse-off formulation. Toxicol In Vitro. 2005;19(7):963-9.

Soni MG, Carabin IG, Burdock GA. Safety assessment of esters of p-hydroxybenzoic acid (parabens). Food Chem Toxicol. 2005;43(7):999-1003.

Statham BN, Smith EV, Bodger OG, Green CM, King CM, Ormerod AD, Sansom JE, English JS, Wilkinson MS, Gawkrodger DJ, Chowdhury MM. Concomitant contact allergy to methylchloroisothiazolinone/ methylisothiazolinone and formaldehyde-releasing preservatives. Contact Dermatitis. 2010;62(1):50-7. 
Tait SW, Green DR. Mitochondria and cell death: outer membrane permeabilization and beyond. Nat Rev Mol Cell Biol. 2010;11(9):621-32.

Thyssen JP, Engkilde K, Lundov MD, Carlsen BC, Menné $\mathrm{T}$, Johansen JD. Temporal trends of preservative allergy in Denmark (1985-2008). Contact Dermatitis. 2010;62(2):102-9.

Tomankova K, Kejlova K, Binder S, Daskova A, Zapletalova J, Bendova H, Kolarova H, Jirova D. In vitro cytotoxicity and phototoxicity study of cosmetics colorants. Toxicol In Vitro. 2011;25(6):1242-50.

Urcan E, Haertel U, Styllou M, Hickel R, Scherthan H, Reichl FX. Real-time xCELLigence impedance analysis of the cytotoxicity of dental composite components on human gingival fibroblasts. Dent Mater. 2010;26(1):51-8.
Vermes I, Haanen C, Steffens-Nakken H, Reutelingsperger C. A novel assay for apoptosis. Flow cytometric detection of phosphatidylserine expression on early apoptotic cells using fluorescein labelled Annexin V. J Immunol Methods. 1995;184(1):39-51.

Yadav A, Kumar A, Das M, Tripathi A. Sodium benzoate, a food preservative, affects the functional and activation status of splenocytes at non cytotoxic dose. Food Chem Toxicol. 2016; 88:40-7.

Zablockaite D, Gendiviliene V, Martisiene I, Jurevicius J. Effect of oxidative phosphorylation uncoupler FCCP and F1F0-ATPase inhibitor oligomycin on the electromechanical activity of human myocardium. Adv Med Sci. 2007;52:89-93.

Received for publication on $27^{\text {th }}$ October 2016 Accepted for publication on $30^{\text {th }}$ August 2017 